\title{
18.2 Million Individuals at Increased Risk of Severe COVID-19 IIIness Are Un- or Underinsured
}

$\mathrm{J}$ Gen Intern Med 35(8):2487-9

DOI: $10.1007 / \mathrm{s} 11606-020-05899-8$

(C) Society of General Internal Medicine 2020

\section{BACKGROUND}

As of April 20, more than 780,000 individuals had confirmed COVID-19 in the USA. ${ }^{1}$ In addition to threatening health, this outbreak could have financial consequences for those affected. One analysis estimated that 5.7 million Americans at high risk for severe COVID-19 are uninsured. ${ }^{2}$ Healthcare costs could deter such individuals from seeking care, particularly among disadvantaged groups, while burdening household finances. We analyzed a nationally representative survey to identify individuals at elevated risk for severe COVID-19 and, among these, those at high risk of financial toxicity from care at the start of the epidemic.

\section{METHODS}

We analyzed the 2018 Behavioral Risk Factor Surveillance System (BRFSS), a survey of the noninstitutionalized population conducted by the Centers for Disease Control (CDC). We identified the "COVID-19-increased risk" population based on $\mathrm{CDC}$ guidance ${ }^{2,3}$ : individuals 65 and older, and non-elderly adults with COPD, asthma, heart disease, severe obesity (BMI $\geq 40$ ), kidney disease, and diabetes.

We first identified demographic characteristics and relevant state-level policies associated with being in the COVID-19increased risk group among adults $<65$. We used multivariable logistic regressions adjusted for age and sex to examine the association between being at COVID-19-increased risk (vs not increased risk) and five characteristics/state-level policies: race, income, urban/rural county of residence, residence in a state that had implemented the Affordable Care Act's Medicaid expansion as of January $2018,{ }^{4}$ and residence in a state that had issued a "stay-at-home" order as of March 30, $2020^{5}$ (as one indicator for outbreak risk).

We next examined the rate of "inadequate insurance" within the high-risk population of any age. Inadequate insurance was defined as being uninsured or underinsured, i.e., insured, but having skipped a doctor visit within the last year because of cost. We examined the relationship between the five characteristics/state-level policies listed

Received April 21, 2020

Accepted April 30, 2020

Published online June 10, 2020 above and inadequate insurance in separate age- and sexadjusted regressions.

We used STATA/SE 16.1 for all analyses, with weights and appropriate methods to account for the BRFSS' complex sampling procedures. Analysis of the BRFSS does not constitute human subjects research per the Cambridge Health Alliance IRB.

\section{RESULTS}

Table 1 displays data on the prevalence of risk factors for severe COVID-19 among those $<65$ years. Blacks, American Indians/Alaska Natives, and those of "other" race were significantly more likely, and Asians less likely, to be in the COVID-increased risk population relative to whites. Persons with lower (vs. high) incomes were more likely to be increased risk, as were those living in rural counties, Medicaid nonexpansion states, and states that had not issued a stay-athome order.

Within the COVID-19-increased risk population of adults, $16.9 \%$ (or 18.2 million individuals) were un- or underinsured. Among this increased risk group, those with low incomes, residing in a rural area, and of non-white race had higher rates of inadequate insurance (Table 2). High-risk persons living in Medicaid non-expansion states had 52\% higher odds of being inadequately insured relative to those in expansion states ( $95 \%$ CI $1.43,1.61 ; p<0.001$ ), and high-risk individuals residing in states that had not issued stay-at-home orders had $23 \%$ higher odds of inadequate insurance relative to those in other states (95\% CI 1.16-1.30).

\section{DISCUSSION}

At the start of the outbreak, 18 million adults at increased risk of severe COVID-19 were inadequately insured and hence at risk of delay in seeking care because of cost concerns and of financial toxicity if hospitalized. Traditionally disadvantaged groups-racial minorities, lowincome persons, and rural residents-were more likely to be at risk of severe COVID-19 (consistent with the experience of previous viral respiratory epidemics ${ }^{6}$ ) and of financial harm. Those living in states that failed to expand Medicaid or issue a stay-at-home order were also at greater risk of severe disease and inadequate coverage.

Gaps in insurance coverage, and states' decisions to reject Medicaid expansion and defer prevention measures, may hence exacerbate the damage wrought by 
Table 1 Population at Increased Risk of COVID-19 Among Adults $<65$ Years of Age*

\begin{tabular}{|c|c|c|c|c|c|c|}
\hline & \multicolumn{2}{|l|}{ Unadjusted } & \multicolumn{4}{|l|}{ Adjusted $^{\dagger}$} \\
\hline & $\begin{array}{l}\text { Not increased risk }(\%) \\
(n=198,238)\end{array}$ & $\begin{array}{l}\text { Increased risk }(\%) \\
(n=85,274)\end{array}$ & Odds ratio & \multicolumn{2}{|c|}{$\begin{array}{l}95 \% \\
\text { confidence } \\
\text { interval }\end{array}$} & $p$ value \\
\hline \multicolumn{7}{|l|}{ Race } \\
\hline White & 73.3 & 26.7 & Reference & & & \\
\hline Black & 68.0 & 32.1 & 1.42 & 1.35 & 1.50 & $<0.001$ \\
\hline Asian & 84.7 & 15.4 & 0.57 & 0.51 & 0.64 & $<0.001$ \\
\hline American Indian, Alaska Native & 60.0 & 40.0 & 1.95 & 1.71 & 2.23 & $<0.001$ \\
\hline Hispanic & 75.5 & 24.5 & 1.06 & 1.01 & 1.12 & 0.031 \\
\hline Other & 68.4 & 31.6 & 1.51 & 1.39 & 1.64 & $<0.001$ \\
\hline \multicolumn{7}{|l|}{ Income $^{\S}$} \\
\hline$<\$ 15 \mathrm{~K}$ & 58.5 & 41.5 & 2.83 & 2.67 & 3.01 & $<0.001$ \\
\hline$\$ 15 \mathrm{~K}-\$$ & 64.4 & 35.6 & 2.29 & 2.18 & 2.42 & $<0.001$ \\
\hline$\$ 25 \mathrm{~K}-\$$ & 71.1 & 28.9 & 1.69 & 1.58 & 1.81 & $<0.001$ \\
\hline$\$ 35 \mathrm{~K}-\$$ & 74.3 & 25.7 & 1.39 & 1.30 & 1.48 & $<0.001$ \\
\hline$\$ 50 \mathrm{~K}+$ & 78.4 & 21.6 & Reference & & & \\
\hline \multicolumn{7}{|l|}{ Countyll } \\
\hline Urban & 74.3 & 25.7 & Reference & & & \\
\hline Rural & 68.6 & 31.4 & 1.27 & 1.22 & 1.33 & $<0.001$ \\
\hline \multicolumn{7}{|l|}{ Medicaid expansion ${ }^{\mathrm{q}}$} \\
\hline Non-expansion state & 72.9 & 27.1 & 1.06 & 1.02 & 1.10 & 0.002 \\
\hline Expansion & 73.9 & 26.1 & Reference & & & \\
\hline \multicolumn{7}{|l|}{ Statewide stay-at-home order ${ }^{\#}$} \\
\hline No & 72.9 & 27.1 & 1.07 & 1.04 & 1.11 & $<0.001$ \\
\hline Yes & 74.2 & 25.8 & Reference & & & \\
\hline
\end{tabular}

*Increased risk defined as adults reporting a diagnosis of chronic obstructive pulmonary disease, history of heart attack, angina/coronary heart disease, cancer (excluding skin cancer), diabetes (excluding pre-diabetes and gestational diabetes), current asthma, and severe obesity (BMI $\geq 40)$. Although the $C D C$ includes liver disease and residence in a nursing home as indicators of high risk, ${ }^{3}$ the BRFSS does not include questions that allow identification of persons with chronic liver disease and excludes institutionalized individuals

${ }^{\prime}$ Adjusted for age (18-24, 25-34, 35-44, or 45-54) and sex (male, female). $N=734$ individuals with don't know, not sure, or refused responses for sex, who were excluded from adjusted analyses

${ }^{*}$ Values imputed by BRFSS for those who do not report racelethnicity

${ }^{\xi_{N}}=42,482$ individuals with missing income among those age $<65$, who were excluded from these analyses

"Based on National Center for Health Statistics' 2013 Urban - Rural Classification Scheme; those in one of the four metropolitan counties are classified as "urban" and those in one of the two non-metropolitan counties are classified as "rural." Excludes 4817 individuals from Guam and Puerto Rico

"Based on summary from the Kaiser Family Foundation; status as of January 2018. ${ }^{4}$ Excludes 4817 individuals from Guam and Puerto Rico among those age $<65$

${ }^{\#}$ Based on summary from the Kaiser Family Foundation; status as of March 30, 2020. ${ }^{5}$ Excludes 4817 individuals from Guam and Puerto Rico among those age $<65$

the COVID-19 epidemic, as well as health disparities. Rising unemployment after the onset of the epidemic in the USA will likely translate into health coverage losses that could further widen these gaps; our estimates of uninsurance and underinsurance are likely underestimates. These findings provide support for steps taken to address inadequacies in coverage for the diagnosis and treatment of COVID-19 and for the consideration of additional policies that could expand coverage during the economic downturn.

Adam W. Gaffney, MD, $M P H^{1,2}$

Laura Hawks, $M D^{1,2}$

David H. Bor, $M D^{1,2}$

Steffie Woolhandler, $M D, M P H^{2,3}$

David U. Himmelstein, $M D^{2,3}$

Danny McCormick, $M D^{1,2}$

${ }^{1}$ Cambridge Health Alliance, 1493 Cambridge Street, Cambridge, MA 02138, USA
${ }^{2}$ Harvard Medical School,

25 Shattuck St, Boston, MA 02115, USA

${ }^{3}$ City University of New York at Hunter College, Silberman Building, New York, NY 548, USA

Corresponding Author: Adam W. Gaffney, MD, MPH; Cambridge Health Alliance 1493 Cambridge Street, Cambridge, MA 02138, USA (e-mail: agaffney@challiance.org).

Funding Information Dr. Hawks received funding support from Institutional National Research Service Award T32HP32715 and from the Cambridge Health Alliance.

\section{Compliance with Ethical Standards:}

Conflict of Interest: The authors report no financial conflicts of interest. Adam Gaffney, David Himmelstein, Steffie Woolhandler, and Danny McCormick serve as leaders of Physicians for a National Health Program (PNHP), a non-profit organization that favors coverage expansion through a single-payer program; however, none of them receives any compensation from that group, although some of Dr. Gaffney's travel on behalf of the organization is reimbursed by it. Drs. Bor and Hawks are members of the organization. 
Table 2 Inadequately Insured Among COVID-Increased Risk Adult Population of All Ages*

\begin{tabular}{|c|c|c|c|c|c|c|}
\hline & \multicolumn{2}{|l|}{ Unadjusted } & \multicolumn{4}{|l|}{ Adjusted $^{\dagger}$} \\
\hline & $\begin{array}{l}\text { Insured, not underinsured }(\%) \\
(n=208,916)\end{array}$ & $\begin{array}{l}\text { Uninsured or underinsured }(\%) \\
(n=28,577)\end{array}$ & Odds ratio & \multicolumn{2}{|c|}{$\begin{array}{l}95 \% \\
\text { confidence } \\
\text { interval }\end{array}$} & $p$ value \\
\hline \multicolumn{7}{|l|}{ Race $^{+}$} \\
\hline White & 87.2 & 12.8 & Reference & & & \\
\hline Black & 77.6 & 22.4 & 1.51 & 1.39 & 1.64 & $<0.001$ \\
\hline Asian & 82.5 & 17.6 & 1.33 & 1.03 & 1.72 & 0.030 \\
\hline American Indian/Alaska Native & 76.8 & 23.2 & 1.58 & 1.30 & 1.92 & $<0.001$ \\
\hline Hispanic & 68.4 & 31.6 & 2.37 & 2.16 & 2.59 & $<0.001$ \\
\hline Other & 77.1 & 22.9 & 1.50 & 1.32 & 1.70 & $<0.001$ \\
\hline \multicolumn{7}{|l|}{ Income $^{\S}$} \\
\hline$<\$ 15 \mathrm{~K}$ & 71.2 & 28.8 & 4.26 & 3.86 & 4.70 & $<0.001$ \\
\hline$<15 \mathrm{~K} 15 \mathrm{~K}$ & 72.8 & 27.2 & 4.27 & 3.90 & 4.68 & $<0.001$ \\
\hline$<25 \mathrm{~K} 25 \mathrm{~K}$ & 80.8 & 19.3 & 2.99 & 2.68 & 3.33 & $<0.001$ \\
\hline$<35 \mathrm{~K} 35 \mathrm{~K}$ & 85.5 & 14.5 & 2.06 & 1.85 & 2.30 & $<0.001$ \\
\hline \multirow{2}{*}{\multicolumn{7}{|c|}{$\begin{array}{l}<\text { SOKSUK } \\
\text { County }\end{array}$}} \\
\hline & & & & & & \\
\hline Urban & 83.3 & 16.8 & Reference & & & \\
\hline Rural & 82.2 & 17.9 & 1.13 & 1.06 & 1.21 & $<0.001$ \\
\hline \multicolumn{7}{|l|}{ Medicaid expansion ${ }^{\text {II }}$} \\
\hline Non-expansion state & 79.6 & 20.4 & 1.52 & 1.43 & 1.61 & $<0.001$ \\
\hline \multirow{2}{*}{\multicolumn{7}{|c|}{ Statewide stay-at-home order ${ }^{\#}$}} \\
\hline & & & & & & \\
\hline No & 81.7 & 18.3 & 1.23 & 1.16 & 1.30 & $<0.001$ \\
\hline Yes & 84.5 & 15.5 & Reference & & & \\
\hline
\end{tabular}

1705 individuals within the COVID-increased risk group were excluded from these analyses because of missing insurance data

*Increased risk defined as any adults ages $\geq 65$ or non-elderly adults reporting a diagnosis of chronic obstructive pulmonary disease, history of heart attack, angina/coronary heart disease, cancer (excluding skin cancer), diabetes (excluding pre-diabetes and gestational diabetes), current asthma, and severe obesity $(B M I \geq 40)$

${ }^{\dagger}$ Adjusted for age (18-24, 25-34, 35-44, 45-54, 65+) and sex (male, female). $N=624$ individuals with don't know, not sure, or refused responses for sex among the COVID-increased risk adult population, who were excluded from adjusted analyses

${ }^{*}$ Values imputed by BRFSS for those who do not report racelethnicity

$\xi_{N}=46,068$ individuals with missing income among the COVID-increased risk adult population, who were excluded from these analyses

"Based on National Center for Health Statistics' 2013 Urban - Rural Classification Scheme; those in one of the four metropolitan counties are classified as "urban" and those in one of the two non-metropolitan counties are classified as "rural." Excludes 3266 individuals among the COVIDincreased risk adult population from Guam and Puerto Rico

"Based on summary from the Kaiser Family Foundation as of January 2018. ${ }^{4}$ Excludes 3266 individuals among the COVID-increased risk adult population from Guam and Puerto Rico

${ }^{\#}$ Based on summary from the Kaiser Family Foundation; status as of March 30, 2020. ${ }^{5}$ Excludes 3266 individuals among the COVID-increased risk adult population from Guam and Puerto Rico

\section{REFERENCES}

1. Coronavirus COVID-19 Global Cases by the Center for Systems Science and Engineering at Johns Hopkins University. https://coronavirus.jhu. edu/map.html. Accessed Apr 20, 2020.

2. Koma W, Claxton G, 2020. How Many Adults Are at Risk of Serious Illness If Infected with Coronavirus? The Henry $J$ Kaiser Family Foundation. March 2020. https://www.kff.org/global-health-policy/issue-brief/howmany-adults-are-at-risk-of-serious-illness-if-infected-with-coronavirus/. Accessed Mar 24, 2020.

3. Centers for Disease Control and Prevention. Coronavirus Disease 2019 (COVID-19). https://www.cdc.gov/coronavirus/2019-ncov/need-extraprecautions/people-at-higher-risk.html. Published February 11, 2020. Accessed Mar 31, 2020.

4. Status of State Action on the Medicaid Expansion Decision. The Henry J. Kaiser Family Foundation. 2020. Available from: https://www.kff.org/ health-reform/state-indicator/state-activity-around-expanding-medicaidunder-the-affordable-care-act/. Accessed Mar 31, 2020.

5. State Data and Policy Actions to Address Coronavirus. The Henry J Kaiser Family Foundation. March 2020. https://www.kff.org/health-costs/issuebrief/state-data-and-policy-actions-to-address-coronavirus/. Accessed Mar 30, 2020.

6. Dee DL, Bensyl DM, Gindler $\mathbf{J}$, et al. Racial and ethnic disparities in hospitalizations and deaths associated with 2009 pandemic Influenza A (H1N1) virus infections in the United States. Ann Epidemiol. 2011;21(8):623-630. https://doi.org/10.1016/j.annepidem.2011.03.002

Publisher's Note: Springer Nature remains neutral with regard to jurisdictional claims in published maps and institutional affiliations. 